\title{
Aronia melanocarpa fruit extract exhibits anti-inflammatory activity in human aortic endothelial cells
}

\author{
D. Zapolska-Downar · D. Bryk • M. Małecki • \\ K. Hajdukiewicz $\cdot$ D. Sitkiewicz
}

Received: 6 April 2011/Accepted: 3 August 2011/Published online: 24 August 2011

(C) The Author(s) 2011. This article is published with open access at Springerlink.com

\begin{abstract}
Background Altered expression of cell adhesion molecules (CAMs) has been implicated in a variety of chronic inflammatory conditions, including atherosclerosis. Regulation of adhesion molecule expression by specific redoxsensitive mechanisms has been reported. Additionally, it has been observed that the extract of Aronia melanocarpa (A. Melanocarpa) fruits, rich in polyphenols, exhibits potent anti-oxidant properties and displays cardioprotective activity.

Methods and results Human aortic endothelial cells (HAECs) were pretreated with various concentrations (primarily $50 \mu \mathrm{g} / \mathrm{mL}$ ) of Aronia Melanocarpa fruit extract prior to treatment with $\mathrm{TNF} \alpha(10 \mathrm{ng} / \mathrm{mL})$ for various periods of time. The surface protein and mRNA expression of ICAM-1 and VCAM-1 were determined using flow cytometry and real-time RT-PCR, respectively. Adhesion of peripheral blood mononuclear leucocytes (PBMLs) to $\mathrm{TNF} \alpha$-treated HAECs was evaluated by an adhesion assay. Activation of NF- $\kappa \mathrm{B}$ was evaluated by measuring NF- $\kappa$ B p65 phosphorylation using flow cytometry. ROS production was determined by reduction in fluorescent $2^{\prime}, 7^{\prime}$-dichlorofluorescein diacetate (DCFH-DA). Tested A. Melanocarpa extract significantly inhibited the expression of ICAM-1 and VCAM-1, attenuated the phosphorylation of NF- $\kappa \mathrm{B}$ p65 and decreased intracellular ROS production in TNF $\alpha$-treated HAECs.
\end{abstract}

D. Zapolska-Downar $(\bowtie) \cdot$ D. Bryk · M. Małecki .

K. Hajdukiewicz $\cdot$ D. Sitkiewicz

Department of Biochemistry and Clinical Chemistry,

The Warsaw Medical University, Banacha 1 Street,

02-097 Warsaw, Poland

e-mail: zapolska@vp.pl
Conclusion We conclude that A. Melanocarpa fruit extract exhibits anti-inflammatory effects in HAECs by inhibiting the expression of endothelial CAMs, activation of NF- $\kappa \mathrm{B}$ and production of ROS.

Keywords Atherosclerosis - Cell adhesion molecules · Aronia Melanocarpa $\cdot$ Nuclear factor- $\kappa \mathrm{B}$.

Reactive oxygen species

\section{Introduction}

Vascular inflammation is a primary event in the pathogenesis of atherosclerosis [1]. Monocytes and lymphocytes dominate in the early atheromatous plaque, and their effector molecules accelerate plaque progression. Furthermore, inflammation can elicit acute coronary syndromes. The vascular inflammatory reaction is mediated by complex interactions between the circulating leucocytes and vascular cells (e.g., endothelial cells and smooth muscle cells). Vascular cells regulate the inflammatory process through the expression of adhesion molecules, cytokines, chemokines and growth factors. In healthy blood vessels, the endothelial cells do not adhere to the cellular constituents of the blood. Some adhesive interactions between circulating leucocytes and endothelial cells are modified by the expression of cell adhesion molecules (CAMs). Various adhesion molecules have been identified on endothelial cells, including intercellular adhesion molecule-1 (ICAM-1) and vascular cell adhesion molecule-1 (VCAM-1) [2]. These molecules are up-regulated in the vascular endothelium in response to inflammatory stimuli, including proinflammatory cytokines, such as tumour necrosis factor- $\alpha$ (TNF $\alpha$ ) and interleukin (IL)-1, which are commonly found in atherosclerotic lesions. Over-expression of ICAM-1 and 
VCAM-1 is a common feature of the atherosclerotic process.

Regulation of ICAM-1 and VCAM-1 expression occurs at the transcription level and is mediated, at least in part, by nuclear factor $-\kappa \mathrm{B}(\mathrm{NF}-\kappa \mathrm{B})$. This transcription factor plays an important role in the development of inflammatory responses by up-regulating the expression of many inflammatory mediators [3]. In non-stimulated cells, NF$\kappa \mathrm{B}$ is mostly present in association with its inhibitory molecules $(\mathrm{I} \kappa \mathrm{B})$. Upon the stimulation of endothelial cells by inflammatory stimuli, I $\kappa \mathrm{B}$ becomes phosphorylated, permitting $\mathrm{NF}-\kappa \mathrm{B}$ to translocate into the nucleus where it binds to the promoter regions of inflammatory target genes, including ICAM-1 and VCAM-1. Previous studies have indicated that this transcription factor may play an important role in the pathogenesis of atherosclerosis. It has been suggested that NF- $\kappa \mathrm{B}$ is a redox-sensitive transcription factor because reactive oxygen species (ROS) may regulate its activity [4].

Aronia Melanocarpa (also known as black chokeberry) is a shrub of the Rosaceae family and originates from North America [5]. The fruits of A. Melanocarpa have traditionally been used in North American folk medicine. In the 20th century, the chokeberry was introduced in the Soviet Union and Eastern Europe and has been cultivated there since then mainly for the production of juice, jam, wine and natural food colourants. Aronia Melanocarpa fruits have a greater content of phenolic constituents than most other blackberries. These include anthocyanins, procyanidins and phenolic acids $[6,7]$.

The high content and composition of the phenolic constituents of A. Melanocarpa seem to be responsible for the wide range of the fruit's potential medicinal and therapeutic effects. It has been demonstrated that chokeberry extract or juice possesses anti-oxidative, anti-viral, antimutagenic, anti-cancer hepatoprotective, anti-inflammatory, gastroprotective or anti-diabetic activities [5-8]. Most of the beneficial activity of $A$ Melanocarpa products is probably due to the high anti-oxidative activity of their polyphenols, especially anthocyanins. Aronia berries possess the highest anti-oxidant capacity among berries and other fruits investigated to date.

Chokeberry fruit derivatives can also have a beneficial effect on several risk factors for cardiovascular disease. The lipid-lowering effect of Aronia fruit juice has been demonstrated in animal and human studies [9, 10]. In the animal model, chokeberry anthocyanins decrease lipid peroxidation [11]. Aronia products might be useful in the prevention and control of diabetes mellitus [12] and in the treatment of obesity disorders [13]. Moreover, chokeberry extract has been shown to reduce blood pressure in patients with metabolic syndrome [8] and in patients after myocardial infarction [14]. Other effects studied include enhanced reduction in levels of cardiovascular risk markers, such as oxy-LDL, CRP, IL-6, sICAM-1, sVCAM-1 or MCP-1, in patients after myocardial infarction [14, 15]. Anti-platelet effects [16] as well as vasoactive and vasoprotective properties in porcine coronary arteries have also been observed [17, 18]. In vitro studies have demonstrated that the A. Melanocarpa fruit extract inhibits $7 \beta$-hydroxycholesterol-induced apoptosis of endothelial cells [19].

In this study, we have examined the hypothesis that commercial extract from A. Melanocarpa fruits can inhibit the cytokine-induced endothelial adhesiveness to peripheral blood mononuclear leucocytes and the expression of adhesion molecules (ICAM-1 and VCAM-1) in endothelial cells. In addition, potential molecular mechanisms associated with such effects, including ROS production and $\mathrm{NF}-\kappa \mathrm{B}$ activation, were studied.

\section{Materials and methods}

\section{Materials}

EBM-2 basal medium, EGM-2 Bulletkit, foetal bovine serum (FBS), Hanks' balanced salt solution (HBSS), trypsin-EDTA and trypsin neutralising solution (TNS) were obtained from LONZA (Switzerland). 3-(4,5-dimethylthiazol-2yl)-2,5-diphenyltetrazolium bromide (MTT), dimethyl sulfoxide (DMSO), non-enzymatic cell dissociation solution, 2' $2^{\prime}$-bis-2-carboxyethyl-5-(and-6)-carboxyfluorescein acetoxymethyl ester (BCECF-AM), pyrrolidine dithiocarbamate (PTDC), ibuprofen and dexamethasone were provided by Sigma (St. Louis, MO, USA). Human recombinant TNF $\alpha$, Phosflow Buffer I, Phosflow Perm Buffer III, phycoerythrin (PE)-labelled mouse antibody against human ICAM-1, VCAM-1, NF- $\kappa$ B p65 and IgG1 (isotype control) were all supplied by Becton Dickinson (San Diego, CA, USA). 2' $7^{\prime}$-dichlorofluorescein diacetate (DCFH-DA) was obtained from Molecular Probes and Ficoll-Paque from Pharmacia (Sweden). A commercial extract from A. Melanocarpa fruit (Aronox) was purchased from Agropharm SA (Poland). This extract contained approximately $53 \%$ of total polyphenols, including $23 \%$ of anthocyanins, $15 \%$ of procyanidins and $12 \%$ of phenolic acids (information supplied by the producer). Prior to use, the extract was dissolved in PBS containing 10\% DMSO $(10 \mathrm{mg} / \mathrm{mL})$ and further diluted with culture medium. Dexamethasone and ibuprofen were dissolved in ethanol and stored at concentrations of 10 and $100 \mathrm{mmol} / \mathrm{L}$, respectively. PDTC was dissolved in medium to a stock solution of $10 \mathrm{mmol} / \mathrm{L}$. All reagents were maintained at $-20{ }^{\circ} \mathrm{C}$, and further dilutions with culture medium were prepared before use. 
Cell culture and experimental conditions

Human aortic endothelial cells (HAECs) were purchased from LONZA and cultured in the endothelial cell growth medium (EGM-2 Bulletkit = EBM-2 + growth supplements $+2 \%$ FBS) according to the manufacturer's instructions. Cells were maintained at $37{ }^{\circ} \mathrm{C}$ in $5 \% \mathrm{CO}_{2}$ in a humidified atmosphere and were used for experiments between passages 3 and 4 (doubling population $\leq 10$ ). When the HAECs reached confluence, they were rested for $5 \mathrm{~h}$ in EBM-2 basal medium supplemented with $10 \%$ FBS, and the cells were pretreated with the A. Melanocarpa extract $(1,10$ or $50 \mu \mathrm{g} / \mathrm{mL})$ for $2 \mathrm{~h}$. The cells were then treated with $\mathrm{TNF} \alpha(10 \mathrm{ng} / \mathrm{mL})$ for the indicated period of time. Cell viability, as determined by trypan blue exclusion and MTT assay, were unchanged under all the experimental conditions used.

Measurement of adhesion molecule expression using flow cytometry

Resting HAECs in 12-well plates were pretreated with the indicated concentrations of A. Melanocarpa extract for $2 \mathrm{~h}$ and then treated with $\mathrm{TNF} \alpha(10 \mathrm{ng} / \mathrm{mL})$ for $16 \mathrm{~h}$. The cells were then detached from the plate surface with a nonenzymatic cell dissociation solution, centrifuged and washed in PBS containing 1\% FBS and resuspended in $100 \mu \mathrm{L}$ of the labelling buffer. Subsequently, the cells were incubated in the dark for $1 \mathrm{~h}$ with PE-conjugated mouse anti-human ICAM-1 and VCAM-1 antibodies. For the isotype control, cells were treated with PE-conjugated mouse anti-IgG $\mathrm{I}_{1}$ antibody. Next, the cells were washed with PBS and analysed (10,000 cells per sample) with a FACSCalibur flow cytometer (Becton Dickinson) using CellQuest Software. After correcting for non-specific binding using the isotype control, mean fluorescence intensity was measured as an indicator of ICAM-1 and VCAM-1 surface protein expression.

\section{Quantitative real-time RT-PCR for ICAM and VCAM} mRNA analysis

Resting HAECs in 6-well plates were pretreated with A. Melanocarpa extract $(50 \mu \mathrm{g} / \mathrm{mL})$ for $2 \mathrm{~h}$ and then treated with TNF $\alpha(10 \mathrm{ng} / \mathrm{mL})$ for $6 \mathrm{~h}$. To determine the ICAM and VCAM mRNA levels, quantitative real-time RT-PCR was performed using a LightCycler system (ABI PRISM ${ }^{\circledR} 7000$ Sequence Detection System, Version 1.1, Applied Biosystems). Total RNA was extracted from approximately $2 \times 10^{6}$ cells by the method of Chomczynski and Sacchi [20] using the TRIzol reagent (Invitrogen) and reverse transcribed using the High-Capacity cDNA Reverse Transcription Kit (Applied Biosystems). To amplify the target genes, appropriate primers were synthesised (Institute of Biochemistry and Biophysics, Poland). The sequences of the forward and reverse primers were as follows: $h-I C A M I F$ : 5'-CTCATCCGCGTGTGTGTGTG-3'; h-ICAM1R: $5^{\prime}$-GG AGGCTGAGGTGGGAGGAT- $3^{\prime} ; h$-VCAM $1 F: 5^{\prime}$-TGGGA AGATGGTCGTGATCC- $3^{\prime}$; and $h$-VCAM $1 R$ : $5^{\prime}$-GCCT GTTGGTGCTGCAAGTC- $3^{\prime}$. The $\beta$-actin gene was used as a reference (housekeeping) gene (forward primer, ActbF: $5^{\prime}$-TGAAGTGTGACGTTGACATCC- $3^{\prime}$ and reverse primer, ActbR: 5'- GCCAGAGCAGTAATCTCCTTC-3'). Reaction mixtures $(20 \mu \mathrm{L})$ consisted of $\mathrm{SYBR}^{\circledR}$ Green PCR Master Mix (Applied Biosystems), the forward and reverse primers and an aliquot of the reverse-transcribed samples (cDNA, $2 \mu \mathrm{L}$ ). Negative controls were tested in parallel. The relative mRNA levels of the studied genes were calculated by the comparative cycle threshold $\left(\mathrm{C}_{\mathrm{T}}\right)$ method (ABI Prism 7000 SDS Software, Version 1.1, Applied Biosystems). $\beta$-actin mRNA levels measured in the same RNA sample for the target $\mathrm{C}_{\mathrm{T}}$ normalisation were used to compute the relative gene expression ratio.

\section{Cell adhesion assay}

Peripheral blood mononuclear leucocytes (PBMLs) were isolated from the blood of healthy volunteers by density gradient centrifugation with Ficoll-Paque. The isolated mononuclear cells were resuspended in a serum-free medium and labelled with $10 \mu \mathrm{mol} / \mathrm{L}$ of BCECF-AM for $1 \mathrm{~h}$ at $37{ }^{\circ} \mathrm{C}$. Non-fluorescent BCECF-AM is lipophilic, and its methylester is cleaved intracellularly and becomes a highly charged fluorescent BCECF that is retained by viable cells. After the labelling, cells were washed twice with PBS containing 5\% FBS and resuspended in the EBM-2 medium at a density of $5 \times 10^{5}$ cells/mL. Resting HAECs in 24-well plates were pretreated with $A$. Melanocarpa extract $(50 \mu \mathrm{g} /$ $\mathrm{mL})$ for $2 \mathrm{~h}$ and then incubated with $\mathrm{TNF} \alpha(10 \mathrm{ng} / \mathrm{mL})$ for 16 h. Fluorescently labelled PBMLs $\left(2.5 \times 10^{5}\right.$ cells/well $)$ were then seeded over the HAEC monolayer and incubated for $1 \mathrm{~h}$ at $37{ }^{\circ} \mathrm{C}$ in $5 \% \mathrm{CO}_{2}$. After the incubation, the mononuclear cell suspension was withdrawn, and the HAECs were washed twice with PBS to remove nonadherent cells. The fluorescence intensity of each well was measured with a fluorescence multi-well reader at excitation and emission wavelengths of 485 and $530 \mathrm{~nm}$, respectively.

Measurement of NF- $\kappa \mathrm{B}$ p65 phosphorylation

Optimal activation of NF- $\kappa \mathrm{B}$ requires phosphorylation in the transactivation domain of $\mathrm{p} 65$. NK- $\kappa \mathrm{B}$ p 65 phosphorylation was determined using flow cytometry using a specific antibody that differentiates between the phosphorylated and non-phosphorylated version of a given protein, as described previously [21]. Resting HAECs cultured in 6-well plates 
were pretreated with $A$. Melanocarpa extract $(50 \mu \mathrm{g} / \mathrm{mL})$ for $2 \mathrm{~h}$ and then incubated with TNF $\alpha(10 \mathrm{ng} / \mathrm{mL})$ for $45 \mathrm{~min}$. The cells were then detached with a non-enzymatic cell dissociation solution and fixed with Phospho Fix Buffer I for $10 \mathrm{~min}$ at $37{ }^{\circ} \mathrm{C}$. To stain intracellular phospho-p65, fixed cells were washed in PBS and permeabilised with Phospho Perm Buffer III on ice for $30 \mathrm{~min}$. Next, cells were resuspended in $100 \mu \mathrm{L}$ of staining buffer (1\% FBS and PBS) and stained with PE-conjugated mouse antibody directed against human phospho-p65 for $2 \mathrm{~h}$ at room temperature in the dark. For the isotype control, cells were treated with PE-conjugated mouse anti-IgG2b $\kappa$ antibody. The cells were then washed and analysed $(10,000$ cells per sample) with a FACSCalibur flow cytometer (Becton Dickinson) using CellQuest Software. After correcting for non-specific binding using the isotype control, the mean fluorescence intensity was measured.

Detection of intracellular reactive oxygen species (ROS) generation

$2^{\prime}, 7^{\prime}$-dichlorofluorescein diacetate (DCFH-DA) was used to estimate the intracellular generation of ROS. The dye is a non-polar compound that readily penetrates cells. Intracellular peroxides, mainly $\mathrm{H}_{2} \mathrm{O}_{2}$, oxidise DCFH-DA to a highly fluorescent compound $\left(2^{\prime}, 7^{\prime}\right.$-dichlorofluorescein (DCF)). Resting HAECs cultured in 24-well plates were pretreated with A. Melanocarpa extract at the indicated concentrations for $2 \mathrm{~h}$ and incubated with $50 \mu \mathrm{mol} / \mathrm{L}$ of DCFH-DA in HBSS for 50 min. Next, cells were washed twice with PBS and incubated with $\mathrm{TNF} \alpha(10 \mathrm{ng} / \mathrm{mL})$ for $1 \mathrm{~h}$, and the plates were then read on a fluorescence plate reader at excitation and emission wavelengths of 485 and $530 \mathrm{~nm}$, respectively. Data were expressed as percentages of control values (DCF fluorescence of wells without A. Melanocarpa extract/TNF $\alpha$ treatment).

\section{Statistical analysis}

Results are expressed as means $\pm \mathrm{SD}$ from the indicated number of experiments. Comparisons were made using the Student's $t$ test. Differences between the experimental groups were considered to be statistically significant at $p<0.05$.

\section{Results}

A. Melanocarpa fruit extract inhibits TNF $\alpha$-stimulated ICAM-1 and VCAM-1 expression in HAECs as well as leucocyte adhesion

As cell adhesion molecules on endothelial cells mediate leucocyte adhesion to the endothelium during inflammation,
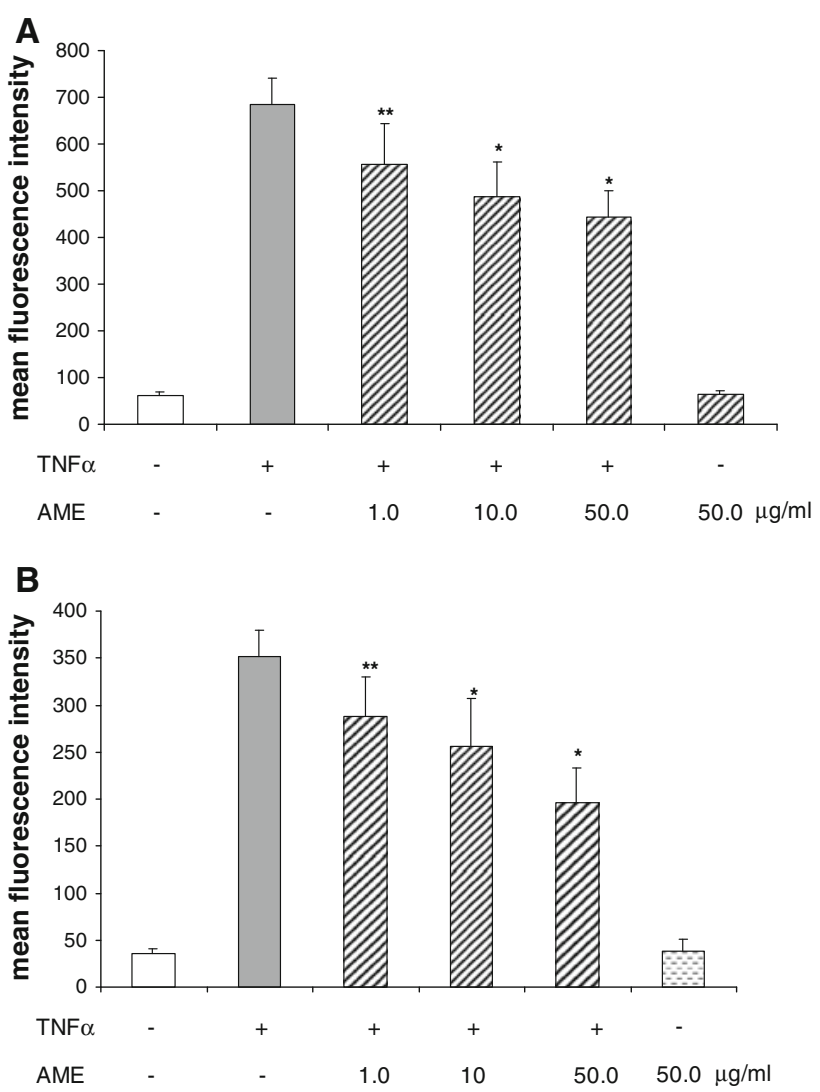

Fig. 1 Effect of A. Melanocarpa extract (AME) on TNF $\alpha$-induced ICAM-1 (a) and VCAM-1 (b) surface expression on endothelial cells. HAECs were incubated without (control) or with the indicated concentration of AME for $2 \mathrm{~h}$ and then incubated with TNF $\alpha(10 \mathrm{ng} /$ $\mathrm{mL}$ ) or TNF $\alpha$ alone for $16 \mathrm{~h}$. Next, cells were stained for ICAM-1 and VCAM-1 and analysed using flow cytometry. Data are expressed as mean fluorescence intensity corrected for non-specific binding and are shown as mean $\pm \mathrm{SD}$ of 6 separate experiments. $* * p \leq 0.01$ and $* p \leq 0.001$ as compared to TNF $\alpha$-treated cells

we investigated the effects of $A$. Melanocarpa extract on TNF $\alpha$-induced ICAM-1 and VCAM-1 expression. Our flow cytometry results demonstrated that resting HAECs exhibited low levels of surface ICAM-1 and VCAM-1 (Fig. 1). As per previous studies, the treatment of HAECs with $\mathrm{TNF} \alpha$ to mimic inflammatory conditions induced higher than a 10-fold increase in ICAM-1 and VCAM-1 surface expression. Pretreatment with chokeberry extract significantly suppressed the TNF $\alpha$-stimulated expression of ICAM-1 and VCAM-1 in a dose-dependent manner: at $50 \mu \mathrm{g} / \mathrm{mL}$, chokeberry extract reduced the levels of expression by about 35 and $45 \%$, respectively. Treatment of HAEC with A. Melanocarpa extract alone had no effect on constitutively expressed levels of ICAM-1 or VCAM-1.

To understand the mechanism responsible for the inhibition of ICAM-1 and VCAM-1 by A. Melanocarpa extract, we examined whether this extract blocks TNF $\alpha$ induced ICAM-1 and VCAM-1 mRNA levels. As shown in 
Fig. 2, stimulation with $\mathrm{TNF} \alpha$ led to a marked increase in ICAM-1 and VCAM-1 mRNA levels in HAECs. Pretreatment with $50 \mu \mathrm{g} / \mathrm{mL}$ chokeberry extract caused a significant decrease in ICAM-1 and VCAM-1 mRNA expression (about 57 and $60 \%$, respectively) as compared to $\mathrm{TNF} \alpha$-treated HAECs. These results indicate that $A$. Melanocarpa fruit extract inhibits the transcription of ICAM-1 and VCAM-1 genes.

We checked the functional importance of the inhibitory properties of chokeberry fruit extract for the TNF $\alpha$-induced expression of ICAM-1 and VCAM-1 by investigating the adhesion of freshly isolated PBMLs to HAECs. Control HAECs showed minimal binding to PBMLs, but treatment with $\mathrm{TNF} \alpha$ led to an approximately fourfold increase in adhesion (Fig. 3). Pretreatment with A. Melanocarpa fruit
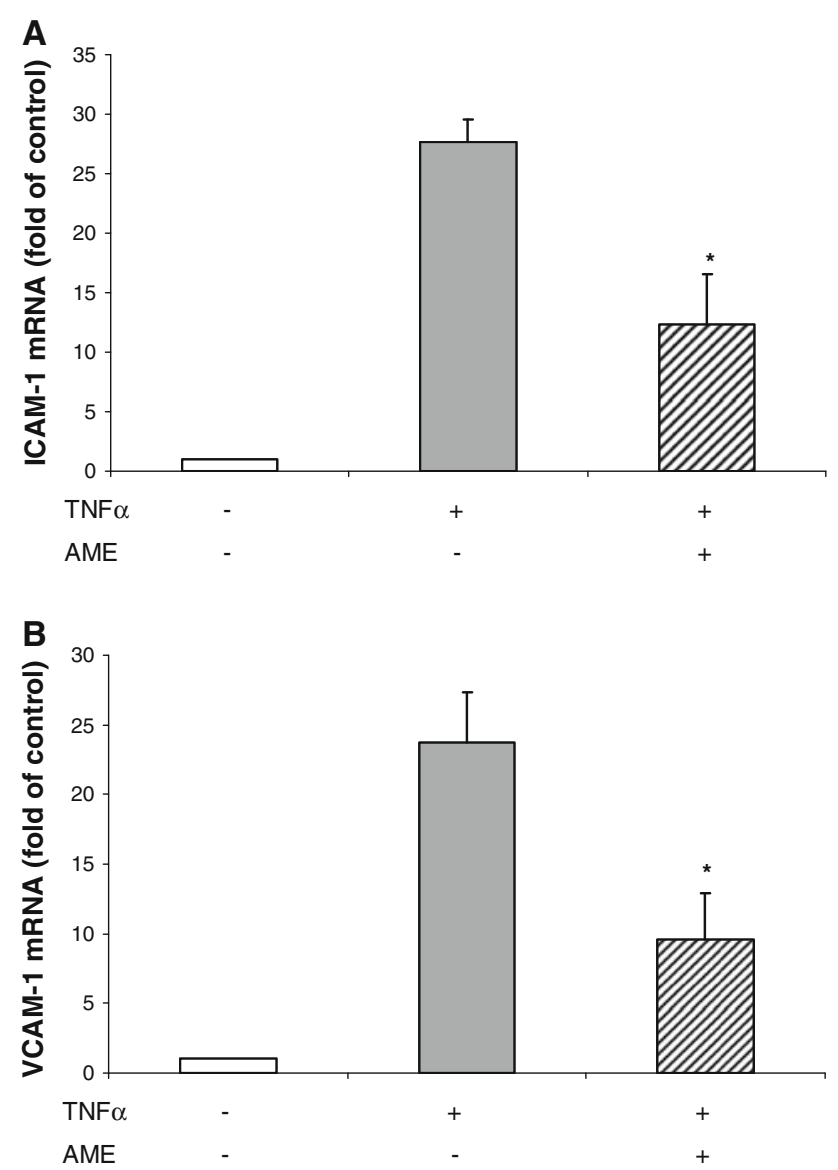

Fig. 2 Effects of A Melanocarpa extract (AME) on TNF $\alpha$-induced ICAM-1 (a) and VCAM-1 (b) mRNA expression in endothelial cells. HAECs were incubated without (control) or with AME $(50 \mu \mathrm{g} / \mathrm{mL}$ for $2 \mathrm{~h}$ and then incubated with $\mathrm{TNF} \alpha(10 \mathrm{ng} / \mathrm{mL})$ or TNF $\alpha$ only for $6 \mathrm{~h}$. Total RNA was isolated, and the mRNA levels of ICAM-1 and VCAM-1 were analysed by quantitative real-time RT-PCR as described in "Materials and methods". The expression levels of the control gene were set to 1 , and the values are normalised to $\beta$-actin. Data are expressed as a multiple of the control and are shown as mean $\pm \mathrm{SD}$ of 7 separate experiments. ${ }^{* *} p \leq 0.01$ and $* p \leq 0.001$ as compared to TNF $\alpha$-treated cells extract $(50 \mu \mathrm{g} / \mathrm{mL})$ significantly reduced the adhesion (about $42 \%$ ) of PBMLs to TNF $\alpha$-stimulated HAECs.

A. melanocarpa fruit extract attenuates the phosphorylation of NF- $\kappa \mathrm{B}$ p65 in TNF $\alpha$-stimulated HAECs

$\mathrm{NF}-\kappa \mathrm{B}$ is a potent pro-inflammatory transcription factor, and activation of NF- $\kappa \mathrm{B}$ is a central event in the inflammatory response. Optimal activation of $\mathrm{NF}-\kappa \mathrm{B}$ requires the phosphorylation of p65. Therefore, to examine whether the inhibitory effect of chokeberry fruit extract on the TNF $\alpha$ induced expression of adhesion molecules is mediated by this transcription factor, we measured the phosphorylation of NF- $\kappa \mathrm{B}$ p65 using flow cytometry. Incubation of HAECs with $\mathrm{TNF} \alpha$ for $45 \mathrm{~min}$ induced the phosphorylation of NF$\kappa \mathrm{B}$ p65 (Fig. 4). Pretreatment with $50 \mu \mathrm{g} / \mathrm{mL}$ A. Melanocarpa fruit extract significantly attenuated the phosphorylation of $\mathrm{NF}-\kappa \mathrm{B}$ p65 in $\mathrm{TNF} \alpha$-stimulated HAECs.

\section{A. Melanocarpa fruit extract inhibits intracellular ROS production}

ROS produced by various stimuli contribute to the intracellular signalling pathways associated with the inflammatory response, including NF- $\kappa \mathrm{B}$ activation [4]. As tested chokeberry fruit extract inhibited $\mathrm{TNF} \alpha$-induced $\mathrm{NF}-\kappa \mathrm{B}$ activation, we therefore examined the effect of $A$. Melanocarpa fruit extract on TNF $\alpha$-stimulated ROS production in HAECs. As shown in Fig. 5, there was an approximately twofold increase in intracellular ROS generation upon stimulation of the HAECs with TNF $\alpha$. Treatment of endothelial cells with fruit extract prior to incubation with $\mathrm{TNF} \alpha$ significantly inhibited intracellular ROS generation in a dose-dependent manner. Unstimulated HAECs (no added $\mathrm{TNF} \alpha$ ) treated with $A$. Melanocarpa extract (50 $\mu \mathrm{g}$ / $\mathrm{mL}$ ) showed significantly decreased DCF fluorescence, as compared to non-extract-treated controls ( $p \leq 0.001)$.

Comparison between A. Melanocarpa fruit extract and a panel of drugs with known anti-inflammatory and/or anti-oxidant activity in inhibiting the TNF- $\alpha$ stimulated expression of ICAM-1 and VCAM-1

In the next step, using the same model of TNF $\alpha$-stimulated HAECs, we compared the inhibitory effect of A. Melanocarpa extract on pro-inflammatory responses in endothelial cells with those of other drugs with well-known antiinflammatory and/or anti-oxidant activities. As shown above, tested chokeberry extract at a concentration of $50 \mu \mathrm{g} / \mathrm{mL}$ reduced ICAM-1 and VCAM-1 expression by about 35 and $45 \%$, respectively. Dexamethasone at a concentration of $100 \mu \mathrm{mol} / \mathrm{L}$ reduced $\mathrm{TNF} \alpha$-induced 
Fig. 3 Effect of

A. Melanocarpa extract (AME) on $\mathrm{TNF} \alpha$-induced adhesiveness of endothelial cells for peripheral blood mononuclear leucocytes. HAECs were incubated without (control) or with AME $(50 \mu \mathrm{g} / \mathrm{mL})$ for $2 \mathrm{~h}$ and then incubated with TNF $\alpha$ (10 $\mathrm{ng} / \mathrm{mL}$ ) or $\mathrm{TNF} \alpha$ only for 16 h. Peripheral blood mononuclear leucocytes (PBMNLs) were labelled with BCECF-AM, and binding to the endothelial cells was quantified as described in "Materials and methods". a Photographic view of PBMNLs adhered to HAECs. (a) control, (b) TNF $\alpha$ and (c) $\mathrm{AME}+\mathrm{TNF} \alpha$. b Data are summarised and plotted. Values are expressed as \% of control (set at $100 \%$ ) and are shown as mean $\pm \mathrm{SD}$ of 5 separate experiments, each performed in triplicate. $* p \leq 0.001$ as compared to $\mathrm{TNF} \alpha$-treated cells
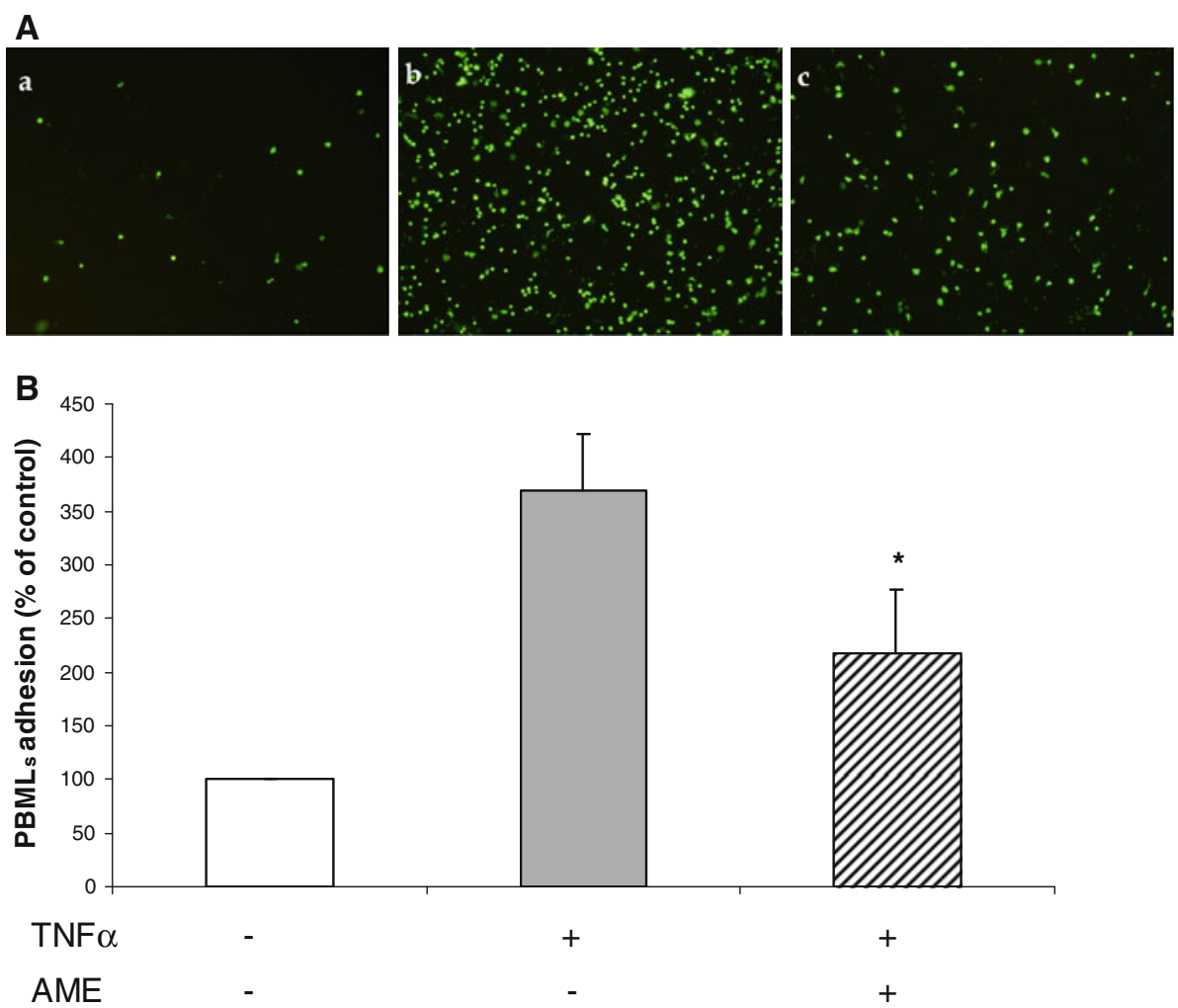

ICAM-1 and VCAM-1 only by approximately 25 and $23 \%$, respectively (Fig. 6). Both ibuprofen and PDTC showed similar effects on VCAM-1 expression as A. Melanocarpa fruit extract. Ibuprofen $(1 \mathrm{mmol} / \mathrm{L})$ inhibited $\mathrm{TNF} \alpha$ induced VCAM-1 expression by approximately $51 \%$ and PDTC $(100 \mu \mathrm{mol} / \mathrm{L})$ by $47 \%$. However, the effect of ibuprofen and PDTC on ICAM-1 expression was much smaller than that of tested chokeberry extract. Ibuprofen reduced TNF $\alpha$-induced ICAM-1 expression by approximately $23 \%$ and PDTC by $28 \%$.

\section{Discussion}

Inflammation plays an important role in atherosclerosis development and progression as well as in atheromatous plaque rupture and, thus, in the onset of acute clinical complications [1]. An early stage in the inflammatory process is endothelial activation, which is directly responsible for the recruitment of circulating leucocytes. This process is self-maintaining and is mediated through the cell adhesion molecules expressed on the surface of endothelial cells, including ICAM-1 and VCAM-1 [2]. Pharmacological agents that display an inhibitory effect on endothelial cell activation should have anti-inflammatory activity. The tested extract was a commercially available preparation of chokeberry, which is a condensed source of polyphenols, especially anthocyanin glycosides.
In the present study, we provide new evidence that the A. melanocarpa extract, rich in polyphenols, can inhibit the pro-inflammatory response of endothelial cells. We found that this chokeberry extract down-regulated $\mathrm{TNF} \alpha$-induced ICAM-1 and VCAM-1 surface protein expression in a concentration-dependent manner. In addition, real-time RT-PCR analysis showed that the suppressive effect of the A. melanocarpa extract on the expression of surface endothelial cell adhesion molecules was correlated with their mRNA levels. Thus, it may be suggested that the observed effect of the tested extract might be due to its influence on the mechanisms regulating the transcription of the genes encoding these molecules.

One of the functional consequences of inhibiting the surface expression of adhesion molecules should be a decrease in endothelial adhesive properties for leucocytes. Indeed, in our study, we showed that preincubation of the HAECs with $A$. melanocarpa fruit extract resulted in a reduction in $\mathrm{TNF} \alpha$-stimulated increased adhesiveness for PBMLs. Because adhesion is one of the earliest steps in inflammation and atherosclerosis, leading to the subsequent migration of blood leucocytes into the sub-endothelial space, the decrease in the adhesive properties of activated endothelial cells may be an important mechanism by which A. Melanocarpa fruit exerts its anti-inflammatory and antiatherogenic effects.

The NF- $\kappa \mathrm{B}$ redox-sensitive transcription factor plays a key role in TNF $\alpha$-induced ICAM-1 and VCAM-1 

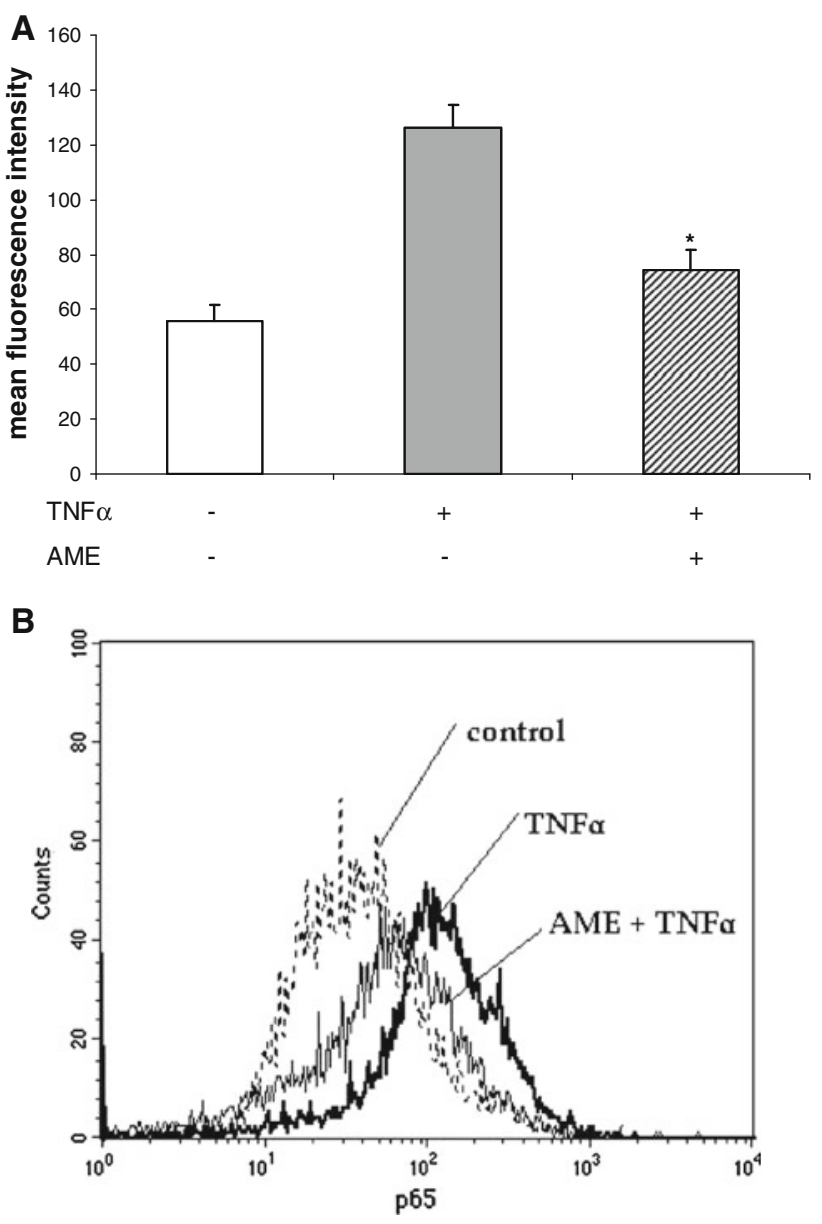

Fig. 4 Effect of A. Melanocarpa extract (AME) on TNF $\alpha$-induced phosphorylation of NF- $\kappa$ B. HAECs were incubated without (control) or with AME $(50 \mu \mathrm{g} / \mathrm{mL})$ for $2 \mathrm{~h}$ and then incubated with $\mathrm{TNF} \alpha$ $(10 \mathrm{ng} / \mathrm{mL}$ ) or TNF $\alpha$ only for $45 \mathrm{~min}$. a Data are expressed as mean fluorescence intensity corrected for non-specific binding and are shown as mean $\pm \mathrm{SD}$ of 8 separate experiments. ${ }^{*} p \leq 0.001$ as compared to TNF $\alpha$-treated cells. b Representative histograms of typical experiments showing the effect of AME on TNF $\alpha$-stimulated phosphorylation of NF- $\kappa \mathrm{B}$ ( $\log$ PE fluorescence on the X-axis)

expression [3]. Its role in the pathogenesis of atherosclerosis has been indicated by studies showing that its active form is present in atherosclerotic lesions [22], and the intensification of immunoreactivity for active form of NF$\kappa \mathrm{B}$ is more pronounced in patients with unstable ischaemic disease as compared with its stable form [23]. The optimal activation of NF- $\kappa \mathrm{B}$, allowing its binding to the appropriate promoter regions, requires phosphorylation in the transactivation domain of the p65 protein. Thus, we decided to evaluate the effects of the investigated extract on NF- $\kappa$ B activation by measuring the extent of $\mathrm{p} 65$ phosphorylation using specific antibodies that recognise only the phosphorylated form. In the present study, we found that TNF $\alpha$ induced higher levels of NF- $\kappa \mathrm{B}$ phosphorylation that could be decreased in HAECs when pretreated with the polyphenol-rich A. melanocarpa extract. These results suggest

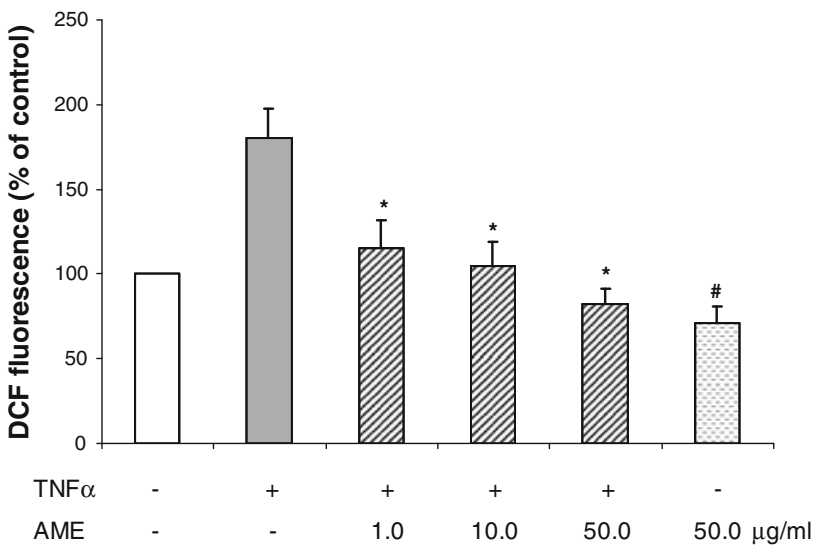

Fig. 5 Effect of A. Melanocarpa extract (AME) on TNF $\alpha$-induced intracellular ROS generation in endothelial cells. HAECs were incubated without (control) or with AME $(50 \mu \mathrm{g} / \mathrm{mL})$ for $2 \mathrm{~h}$, and the cells were then loaded with DCFH DA $(50 \mu \mathrm{mol} / \mathrm{L})$ for $45 \mathrm{~min}$ and were treated with $\mathrm{TNF} \alpha(10 \mathrm{ng} / \mathrm{mL})$ for $1 \mathrm{~h}$. The conversion of DCFH to DCF was measured as described in "Materials and methods". Values are expressed as \% of control DCF fluorescence (set at 100\%) and are shown as mean \pm SD of 10 separate experiments. $* p \leq 0.001$ as compared to the TNF $\alpha$-treated cells; $\# \mathrm{p} \leq 0.001$ as compared to the control

that the anti-inflammatory properties of this extract in vitro are mediated, at least in part, by the inhibition of NF- $\kappa \mathrm{B}$ activation.

Several studies have indicated that ROS are implicated in the activation of NF- $\kappa \mathrm{B}$. [4]. It is postulated that ROS interfere with signalling pathways, which leads to phosphorylation and subsequent $\mathrm{I} \kappa \mathrm{B}$ degradation. Our study has shown that the chokeberry extract lowers the intracellular ROS production not only in cells exposed to TNF $\alpha$ but also in quiescent ones.

Based on the results of our study, we assume that the inhibitory effect of A. melanocarpa fruit extract on ICAM-1 and VCAM- 1 expression and NF- $\kappa$ B activation may be due to anti-oxidant properties.

Finally, the inhibitory effects of A. Melanocarpa fruit extract were compared with those of other drugs with wellknown anti-inflammatory and/or anti-oxidant activities, such as dexamethasone, ibuprofen and PDTC. Studies conducted in the same conditions demonstrated that the extent of the inhibitory effect of the tested chokeberry extract on the TNF $\alpha$-induced VCAM-1 expression was similar to that of ibuprofen and PDTC. The effect of A. Melanocarpa extract on TNF $\alpha$-stimulated ICAM expression was much greater than that observed for ibuprofen and PDTC, while dexamethasone reduced TNF $\alpha$ induced ICAM-1 and VCAM-1 expression to only a minor extent despite its strong anti-inflammatory activity. The differences observed are most likely due to varying mechanisms of action. The principal mechanism of action of dexamethasone is the so-called negative regulation by 

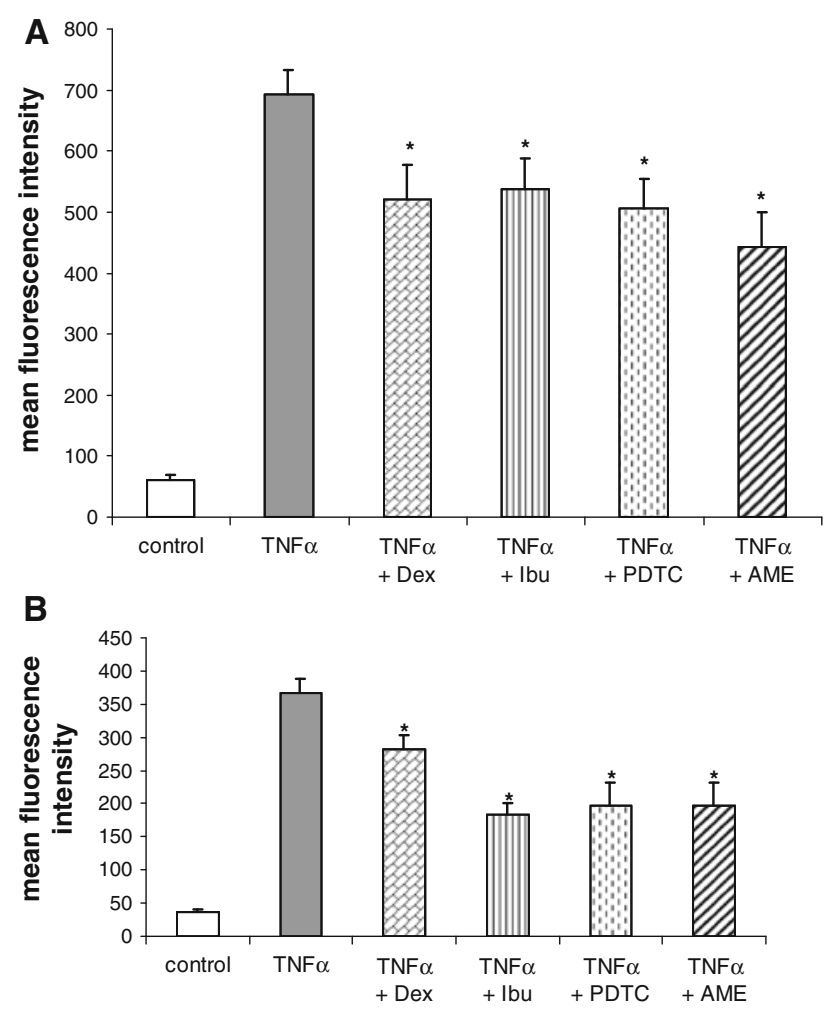

Fig. 6 Comparison between A. Melanocarpa extract (AME) and the panel of anti-inflammatory and/or anti-oxidant drugs on the expression of ICAM-1 (a) and VCAM-1 (b) in HAECs stimulated with TNF. HAECs were pretreated with dexamethasone (Dex) $(100 \mu \mathrm{mol} /$ L), ibuprofen (Ibu) $(1 \mathrm{mmol} / \mathrm{L})$, PDTC $(100 \mu \mathrm{mol} / \mathrm{L})$ and AME extract $(50 \mu \mathrm{g} / \mathrm{mL})$ for $2 \mathrm{~h}$ and then incubated with TNF $\alpha(10 \mathrm{ng} /$ $\mathrm{mL}$ ) or TNF $\alpha$ only for $16 \mathrm{~h}$. Next, the cells were stained for ICAM-1 and VCAM-1 and analysed using flow cytometry. Data are expressed as mean fluorescence intensity corrected for non-specific binding and are shown as mean $\pm \mathrm{SD}$ of 6 separate experiments. ${ }^{*} p \leq 0.001$ as compared to $\mathrm{TNF} \alpha$-treated cells

glucocorticoid receptor (GR) (transrepression), which occurs via different mechanisms [24]. The most intensively investigated mechanism is the ability of the GR to inhibit the activity of other transcription factors through molecular interactions known as tethering. The transcription factors to which GR is tethered include NF- $\kappa \mathrm{B}$ and activator protein1 (AP-1), another transcription factor which is activated by most agents that activate NF- $\kappa \mathrm{B}$ [25]. The activation of both NF- $\kappa \mathrm{B}$ and AP-1 is in most cases dependent on the production of ROS [26]. We observed a minor effect on the $\mathrm{TNF} \alpha$-stimulated expression of both ICAM- 1 and VCAM1 that may be caused by the fact that the drug simultaneously enhances the production of ROS in endothelial cells [27]. PDTC is a known inhibitor of NF- $\kappa \mathrm{B}$ activation [28] and may exert its effect via binding to the superoxide anion, thus reducing the formation of $\mathrm{H}_{2} \mathrm{O}_{2}$, which seems to be the principal NF- $\kappa \mathrm{B}$ activator [4]. The inhibitory effects of PDTC on VCAM-1 expression, which were much stronger than those exerted on ICAM-1 expression, have also been observed by other authors; these effects result probably from the fact that oxidative stress-dependent NF- $\kappa$ B activation is crucial for the stimulation of VCAM-1 expression but is not the only factor required for ICAM-1 induction [29, 30]. The effect of ibuprofen was similar to that of PDTC, which is consistent with other reports [31]. The available literature suggests that ibuprofen inhibits the activation of NF- $\kappa \mathrm{B}$ by blocking the activity of phosphorylating kinases $\mathrm{I} \kappa \mathrm{B}$ [32]. Despite a lack of direct evidence, the similar effects of ibuprofen and PDTC on TNF $\alpha$-stimulated VCAM- 1 expression are thought to be due to the fact that both ibuprofen and PDTC are scavengers of hydroxyl radicals [33].

A. Melanocarpa fruit extract contains $53 \%$ polyphenols of which the majority (23\%) consist of anthocyanins, mainly cyanidin-3-glucoside. There are conflicting reports in the literature regarding the effects of anthocyanins on the TNF $\alpha$ stimulated expression of ICAM-1 and VCAM-1. Studies conducted by Nizamutdinov et al. [34] demonstrated that anthocyanins from black soybean seed coats, mainly cyanidin-3-glucoside, delphinidin-3-glucoside and petunidin-3glucoside, inhibited TNF $\alpha$-induced VCAM- 1 but not ICAM1 expression. Other studies have also shown that the same anthocyanins inhibited both TNF $\alpha$-induced VCAM- 1 and ICAM-1 expression through an NF- $\kappa$ B-dependent pathway [35]. A. Melanocarpa extract also contains $12 \%$ phenolic acids. Recent studies have shown that caffeic acid also reduces TNF $\alpha$-induced ICAM- 1 and VCAM- 1 by inhibiting NF- $\kappa \mathrm{B}$ activation [36]. Despite the fact that all tested substances inhibited the activation of NF- $\kappa \mathrm{B}$, it was the tested chokeberry extract that had the greatest effect on the proinflammatory activation of endothelial cells.

The concentration range of the tested extract $(1-50 \mu \mathrm{g} /$ $\mathrm{mL}$ ) was similar to that used in other studies [16]. Similar concentrations have been applied for other plant extracts rich in polyphenols $[37,38]$. The A. melanocarpa berry extract used in this study at $50 \mu \mathrm{g} / \mathrm{mL}$ contained approximately $25 \mu \mathrm{mol} / \mathrm{L}$ of anthocyanin glycosides and $50 \mu \mathrm{mol} /$ $\mathrm{L}$ of total polyphenols. Similar concentrations were adopted in vitro studies employing single polyphenols, such as cyanidin glycoside $(1-100 \mu \mathrm{mol} / \mathrm{L})$ or chlorogenic acid $(25-50 \mu \mathrm{mol} / \mathrm{L})[39,40]$. However, it is most likely that the achievement of such levels in the blood is not possible. Early studies show that anthocyanin glycosides are absorbed from both the stomach and the small intestine without modification, and their intact forms are detected in both plasma and urine. Depending on the anthocyanin glycoside content in the consumed product, the detected serum levels ranged from 100 to $500 \mathrm{nmol} / \mathrm{L}[41,42]$. Thus, a typical dose of commercial A. melanocarpa fruit extract ( 3 tablets; $45 \mathrm{mg}$ anthocyanins) would not reach the levels of the extract used in our study [6]. However, no studies have been performed yet to determine the human bioavailability 
of anthocyanins or other components from the specific chokeberry preparation used in this study. Additionally, it should be noted that due to the time constraints of the in vitro tests, the reaction threshold is usually obtained at higher concentrations. Moreover, long-term administration of such an extract may lead to the accumulation of active compounds and, thus, to a longer-lasting exposure of cells and the possibility of obtaining the same effect at lower doses. Garcia-Alonso et al. [43] have reported that in spite of the low concentration of anthocyanins found in plasma after the consumption of red wine extract (12 g), an increase in the anti-oxidant capacity and a decrease in circulating MCP-1 levels in the plasma were also observed.

In summary, we found that the A. melanocarpa extract, which is rich in polyphenols, can reduce TNF $\alpha$-induced ICAM-1 and VCAM-1 protein and mRNA expression in HAECs as well as inhibit the TNF $\alpha$-induced increase in mononuclear leucocyte adhesion to HAECs. A. melanocarpa extract also attenuated the $\mathrm{TNF} \alpha$-induced activation of NF- $\kappa \mathrm{B}$ and suppressed the production of ROS in HAECs. These findings may provide new insights into understanding the molecular mechanisms underlying the beneficial effects of $A$. melanocarpa fruits on endothelial cells and imply that these berries or other products rich in anthocyanidins may have therapeutic potential in the prevention of atherosclerosis and other pathological events involving leucocyte adhesion.

Conflicts of interest The authors declare that they have no conflicts of interest.

Open Access This article is distributed under the terms of the Creative Commons Attribution Noncommercial License which permits any noncommercial use, distribution, and reproduction in any medium, provided the original author(s) and source are credited.

\section{References}

1. Libby P (2006) Inflammation and cardiovascular disease mechanisms. Am J Clin Nutr 83:456S-460S

2. Galkina E, Ley K (2007) Vascular adhesion molecules in atherosclerosis. Arterioscler Thromb Vasc Biol 27:2292-2301

3. de Winther MP, Kanters E, Kraal G, Hofker MH (2005) Nuclear factor kappaB signaling in atherogenesis. Arterioscler Thromb Vasc Biol 25:904-914

4. Kunsch C, Medford RM (1999) Oxidative stress as a regulator of gene expression in the vasculature. Circ Res 85:753-766

5. Kokotkiewicz A, Jaremicz Z, Luczkiewicz M (2010) Aronia plants: a review of traditional use, biological activities, and perspectives for modern medicine. J Med Food 13:255-269

6. Kulling SE, Rawel HM (2008) Chokeberry (Aronia melanocarpa) - A review on the characteristic components and potential health effects. Planta Med 74:1625-1634

7. Valcheva-Kuzmanova SV, Belcheva A (2006) Current knowledge of Aronia melanocarpa as a medicinal plant. Folia Med (Plovdiv) 48:11-17
8. Chrubasik C, Li G, Chrubasik S (2010) The clinical effectiveness of chokeberry: a systematic review. Phytother Res 24:1107-1114

9. Skoczynska A, Jedrychowska I, Poreba R, Affelska-Jercha A, Turczyn B, Wojakowska A et al (2007) Influence of chokeberry juice on arterial blood pressure and lipid parameters in men with mild hypercholesterolemia. Pharmacol Rep 59:177-182

10. Valcheva-Kuzmanova S, Kuzmanov K, Mihova V, Krasnaliev I, Borisova P, Belcheva A (2007) Antihyperlipidemic effect of Aronia melanocarpa fruit juice in rats fed a high-cholesterol diet. Plant Foods Hum Nutr 62:19-24

11. Kowalczyk E, Charyk K, Fijalkowski P, Niedworok J, Blaszczyk J, Kowalski J (2004) Protective influence of natural anthocyanins of Aronia melanocarpa on selected parameters of antioxidative status in experimental intoxication with sulphide-2-chloroethyl-3chloropropyl. Polish J Environ Stud 13:339-341

12. Valcheva-Kuzmanova S, Kuzmanov K, Tancheva S, Belcheva A (2007) Hypoglycemic and hypolipidemic effects of Aronia melanocarpa fruit juice in streptozotocin-induced diabetic rats. Methods Find Exp Clin Pharmacol 29:101-105

13. Zielinska-Przyjemska M, Olejnik A, Dobrowolska-Zachwieja A, Grajek W (2007) Effects of Aronia melancarpa polyphenols on oxidative metabolism and apoptosis of neutrophils from obese and non-obese individuals. Acta Sci Pol Technol Aliment 6:75-87

14. Naruszewicz M, Daniewski M, Laniewska I, Pikto-Pietkiewicz W, Millo B, Zapolska-Downar D (2003) Effect of anthocyanins from chokeberry (Aronia melanocarpa) on blood pressure, inflammatory mediators and cell adhesion molecules in patients with a history of myocardial infarction (MI). Atherosclerosis 4(2): 143

15. Naruszewicz M, Laniewska I, Millo B, Dluzniewski M (2007) Combination therapy of statin with flavonoids rich extract from chokeberry fruits enhanced reduction in cardiovascular risk markers in patients after myocardial infarction (MI). Atherosclerosis 194:179-184

16. Ryszawa N, Kawczynska-Drozdz A, Pryjma J, CzesnikiewiczGuzik M, Adamek-Guzik T, Naruszewicz M et al (2006) Effects of novel plant antioxidants on platelet superoxide production and aggregation in atherosclerosis. J Physiol Pharmacol 57:611-626

17. Bell DR, Gochenaur K (2006) Direct vasoactive and vasoprotective properties of anthocyanin-rich extracts. J Appl Physiol 100:1164-1170

18. Bell DR, Burt TD (2007) Phenolic acids contained in anthocyanin enriched extracts from elderberry, bilberry and chokeberry possess endothelium dependent and independent vasorelaxation properties in porcine coronary arteries. Faseb J 21:A366

19. Zapolska-Downar D, Nowicka G, Sygitowicz G, Jarosz M (2008) Anthocyanin-rich Aronox extract from Aronia melanocarpa E protects against 7beta-hydroxycholesterol-induced apoptosis of endothelial cells. Ann Nutr Metab 53:283-294

20. Chomczynski P, Sacchi N (1987) Single-step method of RNA isolation by acid guanidinium thiocyanate-phenol-chloroform extraction. Anal Biochem 162:156-159

21. Perez OD, Krutzik PO, Nolan GP (2004) Flow cytometric analysis of kinase signaling cascades. Methods Mol Biol 263:67-94

22. Brand K, Page S, Rogler G, Bartsch A, Brandl R, Knuechel R, Page M, Kaltschmidt C, Baeuerle PA, Neumeier D (1996) Activated transcription factor nuclear factor-kappa $\mathrm{B}$ is present in the atherosclerotic lesion. J Clin Inves 97:1715-1722

23. Wilson SH, Best PJ, Edwards WD, Holmes DR Jr, Carlson PJ, Celermajer DS, Lerman A (2002) Nuclear factor-kappaB immunoreactivity is present in human coronary plaque and enhanced in patients with unstable angina pectoris. Atherosclerosis 160:147-153

24. Smoak KA, Cidlowski JA (2004) Mechanisms of glucocorticoid receptor signaling during inflammation. Mech Ageing Dev 125:697-706 
25. Karin M, Liu Z, Zandi E (1997) AP-1 function and regulation. Curr Opin Cell Biol 9:240-246

26. Manna SK, Zhang HJ, Yan T, Oberley LW, Aggarwal BB (1998) Overexpression of Mn-superoxide dismutase suppresses TNF induced apoptosis and activation of nuclear transcription factor$\kappa \mathrm{B}$ and activated protein-1. J Biol Chem 273:13245-13254

27. Iuchi T, Akaike M, Mitsui T, Ohshima Y, Shintani Y, Azuma H et al (2003) Glucocorticoid excess induces superoxide production in vascular endothelial cells and elicits vascular endothelial dysfunction. Circ Res 92:81-87

28. Schreck R, Meier B, Männel DN, Dröge W, Baeuerle PA (1992) Dithiocarbamates as potent inhibitors of nuclear factor kappa B activation in intact cells. Exp Med 175:1181-1194

29. Khan BV, Harrison DG, Olbrych MT, Alexander RW, Medford RM (1996) Nitric oxide regulates vascular cell adhesion molecule 1 gene expression and redox-sensitive transcriptional events in human vascular endothelial cells. Proc Natl Acad Sci USA 93:9114-9919

30. Arai T, Kelly SA, Brengman ML, Takano M, Smith EH, Goldschmidt-Clermont PJ, Bulkley GB (1998) Ambient but not incremental oxidant generation effects intercellular adhesion molecule 1 induction by tumour necrosis factor alpha in endothelium. Biochem J 331:853-861

31. Kapiotis S, Sengoelge G, Sperr WR, Baghestanian M, Quehenberger P, Bevec D (1996) Ibuprofen inhibits pyrogen-dependent expression of VCAM-1 and ICAM-1 on human endothelial cells. Life Sci 58:2167-2181

32. Scheuren N, Bang H, Münster T, Brune K, Pahl A (1998) Modulation of transcription factor NF-kappaB by enantiomers of the nonsteroidal drug ibuprofen. Br J Pharmacol 23:645-652

33. Zapolska-Downar D, Naruszewicz M (2001) A pleiotropic antiatherogenic action of ibuprofen. Med Sci Monit 7(4):837-841

34. Nizamutdinova IT, Kim YM, Chung JI, Shin SC, Jeong YK, Seo HG et al (2009) Anthocyanins from black soybean seed coats preferentially inhibit TNF-alpha-mediated induction of VCAM-1 over ICAM-1 through the regulation of GATAs and IRF-1. J Agric Food Chem 57:7324-7330
35. Kim HJ, Tsoy I, Park JM, Chung JI, Shin SC, Chang KC (2006) Anthocyanins from soybean seed coat inhibit the expression of TNF-alpha-induced genes associated with ischemia/reperfusion in endothelial cell by NF-kappaB-dependent pathway and reduce rat myocardial damages incurred by ischemia and reperfusion in vivo. FEBS Lett 580:1391-1397

36. Moon MK, Lee YJ, Kim JS, Kang DG, Lee HS (2009) Effect of caffeic acid on tumor necrosis factor-alpha-induced vascular inflammation in human umbilical vein endothelial cells. Biol Pharm Bull 32:1371-1377

37. Chen JW, Chen YH, Lin FY, Chen YL, Lin SJ (2003) Ginkgo biloba extract inhibits tumor necrosis factor-alpha-induced reactive oxygen species generation, transcription factor activation, and cell adhesion molecule expression in human aortic endothelial cells. Arterioscler Thromb Vasc Biol 23:1559-1566

38. Bagchi D, Bagchi M, Stohs S, Ray SD, Sen CK, Preuss HG (2002) Cellular protection with proanthocyanidins derived from grape seeds. Ann N Y Acad Sci 957:260-270

39. Xia M, Ling W, Zhu H, Ma J, Wang Q, Hou M, Tang Z, Guo H, Liu C, Ye Q (2009) Anthocyanin attenuates CD40-mediated endothelial cell activation and apoptosis by inhibiting CD40induced MAPK activation. Atherosclerosis 202:41-47

40. Chang WC, Chen CH, Lee MF, Chang T, Yu YM (2010) Chlorogenic acid attenuates adhesion molecules upregulation in IL-1beta-treated endothelial cells. Eur J Nutr 49:267-275

41. Cao G, Muccitelli HU, Sánchez-Moreno C, Prior RL (2001) Anthocyanins are absorbed in glycated forms in elderly women: a pharmacokinetic study. Am J Clin Nutr 73:920-926

42. Kay CD, Mazza G, Holub BJ, Wang J (2004) Anthocyanin metabolites in human urine and serum. Br J Nutr 91:933-942

43. Garcia-Alonso M, Minihane AM, Rimbach G, Rivas-Gonzalo JC, de Pascual-Teresa S (2009) Red wine anthocyanins are rapidly absorbed in humans and affect monocyte chemoattractant protein 1 levels and antioxidant capacity of plasma. J Nutr Biochem 20:521-529 